\title{
Radiation effects along a UV-B gradient on species composition and diversity of a shallow-water macrobenthic community in the western Baltic
}

\author{
Markus Molis*, Mark Lenz, Martin Wahl \\ Institut für Meereskunde, Düsternbrooker Weg 20, 24105 Kiel, Germany
}

\begin{abstract}
Although the 'intermediate disturbance hypothesis' (IDH) was originally postulated for marine hard-bottom communities, it has rarely been tested for this community type. We experimentally examined the effects of ambient plus artificially enhanced UV-B radiation (eUV-BR) along an intensity gradient on the abundance of individual species, species composition, and diversity of a macrobenthic community in the western Baltic, Germany. Plots were either exposed each day for 0.5, $1,2,4$, and $8 \mathrm{~h}$ to the maximum expected future UV-BR or were left untreated (= ambient irradiance). Species recruitment and succession on artificial substrata were followed for 5 mo. Transient unimodal patterns for species richness and diversity $H^{\prime}$ were produced along the UV-BR gradient early in succession. The density of the competitively superior mussel Mytilus edulis and the abundance of the foliose green alga Ulvopsis grevillei were positively related to UV-BR exposure; suggesting conditions different from those predicted by the IDH-generated unimodal patterns. Protective shading of substratum by $U$. grevillei and the resultant mitigation of the UV-BR impact for succeeding colonizers may be important in this context. Species composition differed persistently among eUV-BR treatments. In contrast to mussels and U. grevillei, the abundance of red algae was adversely affected by eUV-BR along the disturbance gradient. Our results suggest that expected future UV-BR levels will have limited influence on the diversity of shallow-water macrobenthic fouling assemblages in the western Baltic, whereas their species composition may be affected over longer periods.
\end{abstract}

KEY WORDS: UV-B radiation · Diversity $\cdot$ Intermediate disturbance hypothesis $\cdot$ Disturbance $\cdot$ Protective shading $\cdot$ Ulvopsis grevillei $\cdot$ Mytilus edulis

\section{INTRODUCTION}

Biological diversity has declined during the past decades (e.g. Hughes et al. 1997), a trend which may continue over the next century (Edwards \& Abivardi 1998). Recent extinction rates are 100 to 1000 times greater than pre-human rates extrapolated from fossil records (Pimm et al. 1995). Anthropogenic effects such as habitat destruction and global climate change are major causes of this trend (Tilman et al. 1994, Vitousek et al. 1997). Diversity begets ecosystem productivity (Naeem et al. 1994, Tilman et al. 1996), reliability (Naeem \& Li 1997) and stability (Tilman \& Downing 1994, McGrady-Steed et al. 1997) and may improve the function of ecosystem services, i.e. provision of essen- tial natural products for civilisation e.g. pure water (sensu Ehrlich \& Wilson 1991, Emmerson et al. 2001). Thus, identification of the processes which generate and maintain diversity is mandatory in predicting the effects of human impacts on the persistence of communities and the services they provide (Worm \& Karez 2002).

Earlier models emphasized competition and niche differentiation as the principal mechanisms for the coexistence of species (Hardin 1960, Hutchinson 1961). More recently, stochastic events, e.g. recruitment (Smith \& Witman 1999), disturbance (reviewed in Mackey \& Currie 2001) or both (Menge \& Sutherland 1987) have been used to explain persistence of high diversity. In this context, Connell's (1978) 'intermediate disturbance 
hypothesis' (IDH) is one of the most frequently cited models. The IDH implies a reduced dominance of a competitively superior species in disturbed communities due to its stronger impairment by the disturbance compared to most other species of the system. The IDH predicts maximum diversity at an intermediate level of disturbance due to the release of a limiting resource. Competitive exclusion and harsh environmental conditions can lower diversity under low and high disturbance levels, respectively. As a result, a unimodal diversity pattern results along the disturbance gradient.

Experimental evidence for the validity of the IDH is controversial, with studies either rejecting (e.g. Mook 1981, Tanner et al. 1994, McCabe \& Gotelli 2000) or endorsing (e.g. Fox 1981, Aronson \& Precht 1995, Flöder \& Sommer 1999) it. Such equivocal results may reflect the experimental constraints of the model (Mackey \& Currie 2001) or the fundamental weakness of recognizing and measuring the impact of disturbance (Reynolds et al. 1993).

A great effort has been made to define disturbance and stress with respect to the effects on biomass accrual (Grime 1977), the nature of disturbance (White \& Pickett 1985) and the ecological structure of communities (Pickett et al. 1989). UV-BR features some aspects of disturbance because of its potential to destroy biomass (e.g. Bothwell et al. 1993, Lotze et al. 2002) and to provoke changes in species interactions (e.g. Bothwell et al. 1994, Pavia et al. 1997). Differential mortality of juvenile and adults further strongly implies effects of UV-BR on communities (Wood 1987, Santas et al. 1998).

The nutrient-rich Baltic Sea is a very suitable study site to investigate future UV-BR effects on diversity, because increases in detrimental UV-BR levels will be disproportionately stronger outside the tropics (Wängberg et al. 1996), and with rates too fast for organisms to adapt (WMO 1998). Furthermore, climate-mediated increases in adverse UV-BR impacts have been particularly documented in dissolved organic carbon (DOC)rich systems (Schindler et al. 1996). Our experiments were designed to test for UV-BR effects along a gradient from current ambient levels to the expected maximum around the year 2050 (WMO 1998). We investigated (1) whether diversity responds to a UV-BR gradient as predicted by the IDH, (2) whether enhanced levels of UV-BR beyond a certain intensity have detrimental effects on mussels, the system's dominant competitor, and (3) whether species composition would be affected by our treatments.

\section{MATERIALS AND METHODS}

Experimental site. Settlement plates were submerged in a wave-sheltered bay of an island in Kiel
Fjord, Germany $\left(54^{\circ} 23^{\prime} \mathrm{N}, 10^{\circ} 09^{\prime} \mathrm{E}\right)$ on the SW coast of the Baltic Sea. The blue mussel Mytilus edulis dominates the species-poor ( $<15$ species) hard-bottom community (Molis 2002). Macroalgae show a clear depth distribution pattern, with fucoids dominating shallow water and red algae prevailing in deeper waters. Major predators, i.e. the crab Carcinus maenas and the starfish Asterias rubens, are strictly bottom-dwelling. During the study period, water temperature and salinity ranged between 12 and $18^{\circ} \mathrm{C}$, and between 15 and $19 \%$, respectively.

Experimental design and set-up. Using a randomised block design, we tested a factorial field experiment for the effects of ambient UV-B radiation (controls) and 5 artificially enhanced UV-B radiation (eUV-BR) levels on species composition, community diversity, and the abundance of algae and invertebrates. For eUV-BR treatments, we used lamps (for specifications see next subsection) to enhance UV-BR relative to the ambient UV-B regime (for description of UV-BR treatments see next subsection).

Our field experiment was conducted from 29 May to 30 October 2000. We fixed 6 settlement panels (grey PVC, $70 \times 70 \mathrm{~mm}$, roughened with emery-paper [Grain Type 60]) as procedural controls, in duplicate, to 3 wooden bars (A to C, Fig. 1) to test whether the conditions created by our manipulation confound the interpretation of results. A second set of identical settlement panels $(\mathrm{N}=36)$ was attached to 3 wooden rafts $(10 \times 2.5 \times 0.6 \mathrm{~m})$, each raft (1 to 3 , Fig. 1$)$ representing a single block containing 2 replicates (12 experimental units [EU]). All settlement panels were positioned $10 \mathrm{~cm}$ below the water surface; 10 UV-B lamps were connected along both sides of individual rafts in sealed UV-B-transparent Perspex (GS 2648, Röhm, Germany) housings ( $1.5 \mathrm{~m}$ long, $80 \mathrm{~mm} \varnothing$ ). For the 2 control plots on each raft, no lamp was fixed to the suspension board. Each Perspex tube was lined with non-transparent cardboard in which a $10 \times 10 \mathrm{~cm}$ window was cut. Each panel was irradiated by a separate lamp. Windows were separated by a minimum distance of $40 \mathrm{~cm}$. UV-BR levels in the middle of 2 adjacent windows were not significantly different from control measurements of ambient UV-BR at the same depth (paired $t$-test: $t_{6}=1.94, \mathrm{p}=0.10$ ). During routine inspections every other day, the correct position of the windows was checked and the window area of all housings was rinsed with freshwater to prevent accumulation of salt spray. According to the respective treatment, a programmed electronic timer switched the lamps on and off. A control wiring was installed to ensure proper functioning of timers and lamps. The control wiring consisted of a master-slave switch (Conrad Electronics, Germany) and an electric counter, which recorded operation periods of the lamps as min $\mathrm{d}^{-1}$. Realised 


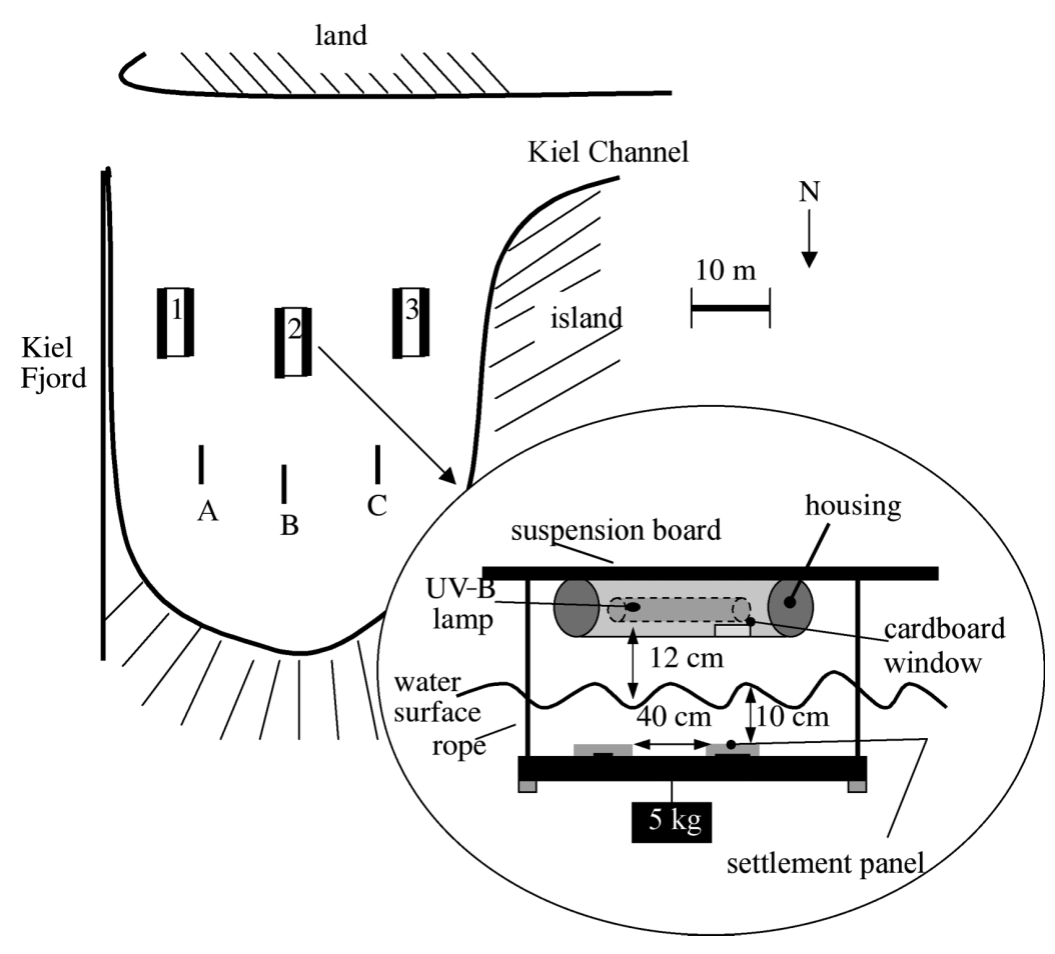

Fig. 1. Position of blocks, i.e. 3 rafts (1 to 3 ) for artificially enhanced UV-B radiation (eUV-BR) treatments and wooden bars (A to $\mathrm{C}$ ) of procedural controls at study site. Black areas of rafts indicate positions of suspended lamps. Inset shows position of a single lamp in relation to settlement panels and suspension board $(10 \times 0.2 \times 0.05 \mathrm{~m})$. (A second settlement panel was irradiated by a second lamp fixed parallel to and behind that shown). For clarity electrical wiring is not shown. Inset is not to scale tion periods of UV-B lamps (Q-Panel UVB-313, USA) were centred around local noon. A single layer of cellulose diacetate filter foil (= CA), blocking wavelengths $<288 \mathrm{~nm}$, was fixed inside housings over the window to absorb all UVCR and most of the UV-BR <293 nm emitted by lamps, but which is not part of the ambient irradiance regime at the earth's surface (Fig. 2). Monthly replacement of foils kept their reduction in transparency due to ageing at $<5 \%$ (pers. obs.). A 1000 W, 8 amp, quartzhalogen lamp (General Electrics, USA) was used as a light source to measure transparency of CA and Perspex tubes in the laboratory. In addition, lamp irradiance with and without CA in Perspex tubes was recorded (Fig. 2). All laboratory measurements were performed with a spectroradiometer (DM 150 double monochromator in Czerny-Turner arrangement, Bentham Instruments, UK), using a Bentham DH3 as the selective photo-multiplier.

Prior to the experiment, UV-B lamps were used for $>1000 \mathrm{~h}$. Their output was measured before and after the experiment, revealing a negligible decrease by $1.4 \pm$ $0.2 \%$ (mean $\pm \mathrm{SD}, \mathrm{n}=8$ ). Although this reduction was wavelength-dependent (with operation periods were protocolled during inspections, and intended treatment periods matched with $>95 \%$ accuracy.

Fine nets ( $1 \mathrm{~cm}$ mesh) were fixed above the water surface. These nets effectively excluded sea birds, as no feeding marks were found on the panels. Nets did not affect radiation flux (paired $t$-test: $t_{5}=$ $1.72, \mathrm{p}=0.15)$.

UV treatments. Averaged over the entire study period, unweighted lamp irradiance received by the settlement panels was $54 \%$ higher than ambient UV-BR at noon (see 'Results' for details). Daily supplements of artificial UV-BR for different periods of time generated an UV-B-intensity gradient with 6 levels viz (1) 0 min (ambient = control), (2) $30 \mathrm{~min}$, (3) $60 \mathrm{~min}$, (4) $120 \mathrm{~min}$ (5) $240 \mathrm{~min}$ and (6) $480 \mathrm{~min}$, resulting in a minimum increase in the daily UV-BR dose of $0,3.5,7,14,27$ and $54 \%$, respectively, based on the assumption that the biological effective UV-BR occurs $\pm 4 \mathrm{~h}$ around local noon. Given as unweighted irradiance, average UV-BR exposure of panels was 0.249 (ambient), 0.258 (30 $\mathrm{min}), 0.266$ (60 $\mathrm{min}), 0.284$ (120 $\mathrm{min})$, 0.316 (240 $\mathrm{min}$ ) and 0.384 (480 $\mathrm{min}) \mathrm{W} \mathrm{m}^{-2}$. Opera-

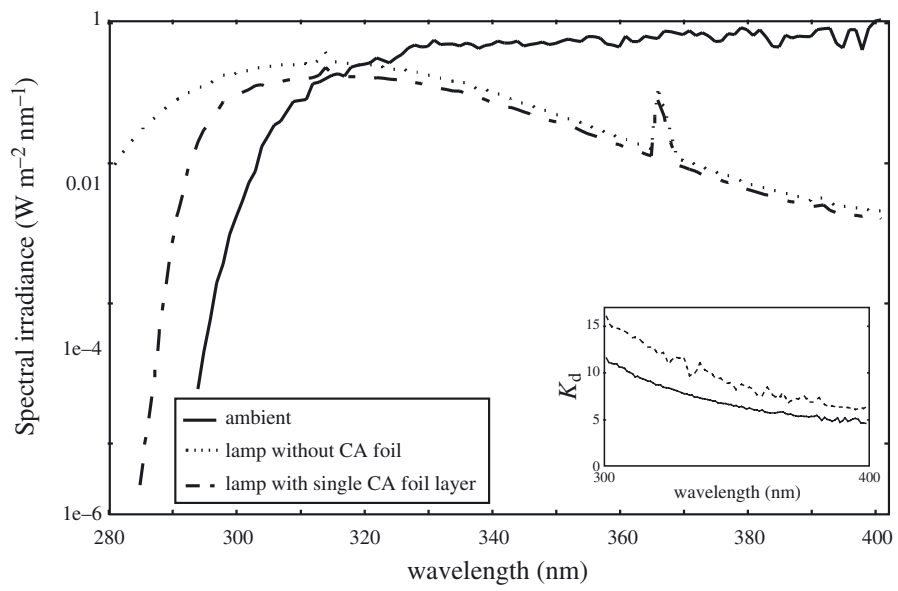

Fig. 2. Unweighted spectra (1 $\mathrm{nm}$ resolution) of above-water ambient irradiance (Westerland, Sylt, Germany [545ㄴ $5^{\prime}$, E $08^{\circ} 19^{\prime}$ E], local noon 28 June 2000), and of lamp irradiance without and with a cellulose diacetate (CA) foil measured in laboratory. Inset: diffuse vertical attenuation coefficients $\left(K_{\mathrm{d}}\right)$ in spectral resolution for lamp irradiance on 30 June 1999 (solid line) and 17 April 2001 (dashed line), calculated from measurements at 10 and $30 \mathrm{~cm}$ water depth. All lamp measurements were made with Perspex tubes used in the experiment (see 'Materials and methods' for details). For clarity, no data beyond UVR range are presented. Note exponential scaling of main graph 
strongest reductions for wavelengths $<300 \mathrm{~nm}$ ), it never exceeded $3 \%$ for single wavelengths $(1 \mathrm{~nm}$ resolution).

In situ radiation measurements. Depth profiles of lamp radiation with $10 \mathrm{~cm}$ resolution from the water surface to $40 \mathrm{~cm}$ water depth were measured at the study site at midnight on 30 June 1999 and 17 April 2001 (June and April measurements with LiCor UV1800 and Bentham DM 150 spectroradiometer, respectively). Spectra (1 $\mathrm{nm}$ resolution) were used to estimate the turbidity of the water at the study site, using the equation $K_{\mathrm{d}}=\ln \left(E_{(0.3 \mathrm{~m})} / E_{(0.1 \mathrm{~m})}\right) \times(0.1 \mathrm{~m}-0.3 \mathrm{~m})^{-1}$, where $K_{\mathrm{d}}$ is the vertical attenuation coefficient of downward irradiance between 0.1 and $0.3 \mathrm{~m}$ water depth and $E$ is the energy of irradiance reaching 0.1 and $0.3 \mathrm{~m}$ water depth. During the experiment, ambient UV-BR was recorded daily every $6 \mathrm{~min}$ over a period of $15 \mathrm{~min}$ before and after local noon (=6 measurements $\mathrm{d}^{-1}$ ) with a UV-B-broadband (280 to $315 \mathrm{~nm}$ ) sensor (Gröbel UV-Elektronik, Germany) at $10 \mathrm{~cm}$ water depth and logged to a laptop. Due to technical problems, no measurements exist for 17 July to 8 September, 15 to 25 September or after 09 October 2000.

Community sampling. From June to October, the abundance of all macroscopic species was estimated as percent cover, and individuals of the blue mussel Mytilus edulis were counted non-destructively in 3 subsamples (40\% of sampled panel area) using a stereomicroscope $(12 \times$ magnification). Sampling was done while communities were completely submerged in a Petri dish with seawater. Colonised panels were replaced, and resampled at monthly intervals. The sampling area discounted a $1 \mathrm{~cm}$ wide band along the panel margin. Using scale paper, subsample area was determined, and mussel counts from single subsamples were normalized to $1 \mathrm{~cm}^{2}$. Diatoms were not identified to species level, but were treated as a group. Species with $<1 \%$ mean cover per panel were excluded from further data-processing. The 3-dimensional structure of communities, caused by, e.g. canopyforming algae or hydroids, sometimes formed multilayered assemblages of $>100 \%$ total cover. Raw data were used to calculate species diversity $H^{\prime}$, species richness $S$, and Pielou evenness $J\left(=H^{\prime} / \ln S\right)$.

Statistical analysis. First, Student's $t$-tests compared controls with procedural controls to explore for artifacts. Second, diversity data were analysed for the entire study period using mixed-model repeatedmeasures ANOVA. Third, only data without significant block effect were pooled and reanalysed with a repeated-measures ANOVA using eUV-BR as a fixed factor. Fourth, because post hoc comparison for eUVBR $\times$ Time interactions are not possible (Winer et al. 1991), an analysis for separate sampling dates is the only way to identify whether and when eUV-BR signif- icantly affected diversity parameters during our experiment. Using a factorial mixed-model ANOVA for separate sampling dates, we tested for effects of eUV-BR on diversity parameters, abundance of individual species and mussel density with UV-BR (6 levels) as fixed, and block (3 levels) as random, factors. Multiple sampling $(k=5)$ required a Bonferroni correction of significance levels of the fixed factor to $\alpha=0.01$ (Sokal \& Rohlf 1995). Fifth, data without a significant block effect were pooled and reanalysed with a linear regression analysis (mussel Mytilus edulis density and Ulvopsis grevillei cover only), a quadratic polynomial regression analysis (diversity parameters) to test for the unimodal pattern, and a 1-factorial ANOVA with UV-BR as a fixed factor (6 levels). To protect results after pooling against Type II error, we further lowered the significance level to $\alpha=0.025$ and 0.005 (Sokal \& Rohlf 1995, Quinn \& Keough 2002) for repeated-measures ANOVA and ANOVAs for separate sampling dates, respectively. Percent data entering the analysis directly were first angular-transformed and, as all data, tested for homogeneity of variances (Cochran's test). When necessary, data were log-transformed to meet the assumptions for ANOVA. A Tukey honest significant difference test followed significant ANOVA results, comparing multiple means at the $\alpha=0.05$ significance level. Using Spearman's rank-correlation, we tested for a relationship between mussel density and U. grevillei abundance. Using the Bray-Curtis similarity index, treatment effects on species composition and the relative contribution of individual species to these differences were assessed with 1-factorial analysis of similarities (ANOSIM) and similarity percentage (SIMPER) analysis, respectively (PRIMER [Plymouth routines in multivariate ecological] software). ANOSIM uses the test statistic $R$, i.e. the difference between average ranked Bray-Curtis index values among replicates between samples and within samples, to identify differences in species composition among samples.

\section{RESULTS}

\section{Radiation measurements}

Monthly ambient UV-BR at $10 \mathrm{~cm}$ water depth was $0.281 \pm 0.11 \mathrm{~W} \mathrm{~m}^{-2}($ mean $\pm \mathrm{SD})$ in June, $0.284 \pm 0.10 \mathrm{in}$ July, $0.179 \pm 0.04$ in September, and $0.158 \pm 0.03$ in October 2000. Ambient UV-BR levels in June were significantly higher than those in October (Kruskal-Wallis $H=9.07, \mathrm{p}=0.028$ ). Averaged over the entire study period, $0.249 \mathrm{~W} \mathrm{~m}^{-2}$ ambient UV-BR reached the settlement panels. At the same water depth, average lamp output $(\mathrm{n}=2)$ was $0.1349 \mathrm{~W} \mathrm{~m}^{-2}$, supplementing ambient UV-BR levels by $54 \%$. Although lamp UV-BR 
comprised only $23 \%$ of total lamp irradiance at $10 \mathrm{~cm}$ water depth, DNA-weighted spectra revealed a >99\% UV-BR share of total lamp output (Table 1).

Vertical attenuation coefficients $\left(K_{\mathrm{d}}\right)$ indicated stronger attenuation of UV-BR in the water than of total UVR (Table 1, Fig. 2). The respective $K_{\mathrm{d}}$ values of UVR and UV-BR were 43 and $41 \%$ higher in April 2001 than in June 1999.

\section{Community structure}

A total of 13 macroscopic species recruited on our panels during the 5 mo of succession. We identified 2 green algae, Ulvopsis grevillei (Thuret) Gayral, 1964 (hereafter Ulvopsis), and Enteromorpha intestinalis L. Link, 2 brown algae, Fucus vesiculosus L. and Pilayella litoralis Kjellm, 3 red algae, Callithamnion corymbosum Lyngb., Ceramium strictum Harvey and Porphyra umbilicalis L., 1763 Kütz, 1843b, and 6 invertebrates, Balanus improvisus Darwin, 1854, Clava multicornis Forskal, Laomedea flexuosa Adler, Membranipora membranacea L., Mytilus edulis L. and Polydora ciliata Johnston. In addition, we encountered benthic diatoms that were recorded as a grouped taxon for which no species identification was made.

\section{Effects on species composition and community diversity}

Procedural controls were not significantly different from controls at any time during species succession with respect to evenness, species composition and diversity. Yet, species richness was significantly lower in controls compared to procedural control panels in September (Student's $t$-test, $t_{8}=-2.66, \mathrm{p}=0.029$ ).

Generally, the mean of all 3 biodiversity measures increased monotonically from June to September and declined in October (Table 2). Averaged over the
Table 1. In situ measurements of UV-BR (300 to $315 \mathrm{~nm}$ ) and UVR (300 to $400 \mathrm{~nm}$ ) in $\mathrm{W} \mathrm{m}^{-2}$ from lamps at study site: Setlow function (Setlow 1974) for DNA-weighted radiation (normalized to $300 \mathrm{~nm})$. Vertical attenuation coefficients $\left(K_{\mathrm{d}}\right)$ were calculated from measurements at 10 and $30 \mathrm{~cm}$ water depth. All measurements made with Perspex and cellulose-diacetate foil (see 'Materials and methods' for details)

\begin{tabular}{|lccrrrrr|}
\hline Radiation & \multicolumn{3}{c}{30 June 1999} & \multicolumn{3}{c|}{17 April 2001 } \\
& $10 \mathrm{~cm}$ & $30 \mathrm{~cm}$ & $K_{\mathrm{d}}$ & $10 \mathrm{~cm}$ & $30 \mathrm{~cm}$ & $K_{\mathrm{d}}$ \\
\hline \multicolumn{3}{l}{ Unweighted } & & & & & \\
UVR & 0.8677 & 0.1843 & 7.75 & 0.2755 & 0.0303 & 11.04 \\
UV-BR & 0.1989 & 0.0267 & 10.04 & 0.0799 & 0.0047 & 14.17 \\
DNA-weighted & & & & & \\
UVR & 0.0297 & 0.0034 & & 0.0138 & 0.0007 & \\
UV-BR & 0.0294 & 0.0033 & & 0.0133 & 0.0007 & \\
\hline
\end{tabular}

entire study period, no significant block effects were detected, while significant UV-B $\times$ block interaction terms were observed only for evenness (Table 3). Reanalysis of pooled data revealed non-significant effects of eUV-BR on evenness, species richness, and diversity $H^{\prime}$, yet all response variables showed a significant eUV-BR $\times$ time interaction, indicating that eUV-BR effects were dependent on community age (Table 3).

Altogether, eUV-BR had little effect on biodiversity in the analysis for individual sampling dates. Only 1 significant block effect was detected, and the respective data set therefor was excluded from further analysis (Table 4). Reanalysis with pooled data revealed no eUV-BR effect on evenness. Treatment effects on species richness and diversity were strongest in July, with significant differences only in diversity (ANOVA, $\left.F_{5,30}=4.50, \mathrm{p}<0.005\right)$. At that time in community succession, diversity was lowest on control and highest on 1 h-exposed panels. Diversity on $>1$ h eUV-BR-treated panels was on average $31 \%$ lower than on the $1 \mathrm{~h}$ exposed panels, but higher than on control panels. A unimodal diversity pattern along the eUV-BR gradient

Table 2. Mean \pm SD evenness $J$, species richness $S$ and diversity $H^{\prime}$ for all sampling dates. Ambient UV-BR: control panels. Ambient + enhanced UV-BR: all panels exposed to irradiance from lamps. $\mathrm{C}_{\mathrm{rel}}$ : average relative change in values between contiguous columns; $\mathrm{n}$ : sample size

\begin{tabular}{|c|c|c|c|c|c|c|c|c|c|}
\hline & June & $\mathrm{C}_{\text {rel }}$ & July & $\mathrm{C}_{\mathrm{rel}}$ & August & $\mathrm{C}_{\mathrm{rel}}$ & September & $\mathrm{C}_{\mathrm{rel}}$ & October \\
\hline \multicolumn{10}{|c|}{ Ambient UV-BR $(\mathrm{n}=6)$} \\
\hline$J$ & $0.60 \pm 0.3$ & 1.36 & $0.72 \pm 0.2$ & 1.14 & $0.79 \pm 0.1$ & 1.11 & $0.86 \pm 0.1$ & 0.96 & $0.83 \pm 0.1$ \\
\hline$S$ & $3.33 \pm 0.8$ & 1.60 & $5.17 \pm 1.0$ & 1.21 & $6.17 \pm 1.2$ & 1.45 & $8.67 \pm 1.4$ & 0.63 & $5.33 \pm 0.8$ \\
\hline$H^{\prime}$ & $0.66 \pm 0.2$ & 1.29 & $0.81 \pm 0.2$ & 1.64 & $1.30 \pm 0.3$ & 1.51 & $1.85 \pm 0.2$ & 0.75 & $1.37 \pm 0.2$ \\
\hline \multicolumn{10}{|c|}{ Ambient + enhanced UV-BR $(\mathrm{n}=30)$} \\
\hline$J$ & $0.63 \pm 0.2$ & 1.22 & $0.67 \pm 0.1$ & 1.21 & $0.78 \pm 0.1$ & 1.08 & $0.83 \pm 0.1$ & 0.99 & $0.82 \pm 0.1$ \\
\hline$S$ & $3.37 \pm 0.7$ & 1.69 & $5.50 \pm 1.1$ & 1.39 & $7.27 \pm 1.1$ & 1.07 & $7.60 \pm 1.0$ & 0.75 & $5.63 \pm 1.4$ \\
\hline$H^{\prime}$ & $0.75 \pm 0.3$ & 1.78 & $1.13 \pm 0.3$ & 1.45 & $1.55 \pm 0.3$ & 1.11 & $1.67 \pm 0.2$ & 0.83 & $1.39 \pm 0.3$ \\
\hline
\end{tabular}


Table 3. Repeated-measures ANOVA. Effects of eUV-BR and block over time (June to October) on evenness $J$, species richness $S$, and diversity $H^{\prime}$; 'pooled': reanalysis without block as a factor for response variables without significant block effect or block $\times$ UV-B interaction term. Numbers in parentheses: df of error terms

\begin{tabular}{|c|c|c|c|c|c|c|c|}
\hline \multirow{2}{*}{ Source } & \multirow[t]{2}{*}{$\mathrm{df}$} & \multicolumn{2}{|c|}{$J$} & \multicolumn{2}{|c|}{$-S$} & \multicolumn{2}{|c|}{$H^{\prime}$} \\
\hline & & $F$ & $\mathrm{p}$ & $F$ & $\mathrm{p}$ & $F$ & $\mathrm{p}$ \\
\hline UV-B (U) & $5(10)$ & 0.42 & 0.822 & 0.89 & 0.524 & 1.74 & 0.214 \\
\hline Block (B) & $2(18)$ & 2.81 & 0.087 & 0.05 & 0.951 & 0.84 & 0.448 \\
\hline $\mathrm{U} \times \mathrm{B}$ & 10 (18) & 2.49 & 0.044 & 0.82 & 0.612 & 0.72 & 0.700 \\
\hline Time (t) & $4(8)$ & 19.13 & $<0.001$ & 89.72 & $<0.001$ & 169.36 & $<0.001$ \\
\hline $\mathrm{T} \times \mathrm{U}$ & $20(40)$ & 1.18 & 0.322 & 1.69 & 0.077 & 1.13 & 0.362 \\
\hline $\mathrm{T} \times \mathrm{B}$ & $8(72)$ & 1.88 & 0.076 & 1.56 & 0.152 & 0.80 & 0.606 \\
\hline $\mathrm{T} \times \mathrm{U} \times \mathrm{B}$ & $40(72)$ & 2.89 & $<0.001$ & 1.66 & 0.030 & 2.49 & $<0.001$ \\
\hline \multicolumn{8}{|l|}{ Pooled } \\
\hline UV-B & $5(30)$ & 0.65 & 0.661 & 0.83 & 0.537 & 1.39 & 0.256 \\
\hline Time & $4(120)$ & 21.31 & $<0.000$ & 111.20 & $<0.001$ & 91.23 & $<0.001$ \\
\hline $\mathrm{U} \times \mathrm{T}$ & 20 (120) & 2.01 & 0.011 & 2.24 & 0.004 & 1.89 & 0.019 \\
\hline
\end{tabular}

Table 4. Mixed-model ANOVA of effects of enhanced UV-BR and block on species evenness $J$, species richness $S$, and diversity $H^{\prime}$ for monthly sampling dates between June and October. Numbers in parentheses: df of error terms

\begin{tabular}{|c|c|c|c|c|c|c|c|}
\hline \multirow{2}{*}{ Source } & \multirow{2}{*}{ df } & \multicolumn{2}{|c|}{$-J$} & \multicolumn{2}{|c|}{$-S$} & \multicolumn{2}{|c|}{$H^{\prime}$} \\
\hline & & $F$ & $\mathrm{p}$ & $F$ & $\mathrm{p}$ & $F$ & $\mathrm{p}$ \\
\hline \multicolumn{8}{|l|}{ June } \\
\hline UV-B & $5(10)$ & 0.69 & 0.646 & 1.64 & 0.237 & 0.39 & 0.844 \\
\hline Block (B) & 2 (18) & 5.40 & 0.015 & 0.76 & 0.482 & 2.09 & 0.153 \\
\hline $\mathrm{UV}-\mathrm{B} \times \mathrm{B}$ & $10(18)$ & 2.83 & 0.026 & 0.38 & 0.942 & 2.91 & 0.023 \\
\hline \multicolumn{8}{|l|}{ July } \\
\hline UV-B & $5(10)$ & 2.26 & 0.127 & 2.58 & 0.095 & 3.58 & 0.041 \\
\hline Block (B) & 2 (18) & 0.39 & 0.683 & 1.55 & 0.239 & 0.24 & 0.792 \\
\hline $\mathrm{UV}-\mathrm{B} \times \mathrm{B}$ & $10(18)$ & 1.49 & 0.220 & 1.84 & 0.124 & 1.33 & 0.286 \\
\hline \multicolumn{8}{|l|}{ August } \\
\hline UV-B & $5(10)$ & 0.27 & 0.922 & 0.63 & 0.684 & 0.71 & 0.633 \\
\hline Block (B) & $2(18)$ & 1.42 & 0.269 & 1.17 & 0.333 & 1.85 & 0.186 \\
\hline$U V-B \times B$ & $10(18)$ & 1.96 & 0.103 & 2.45 & 0.047 & 1.40 & 0.258 \\
\hline \multicolumn{8}{|l|}{ September } \\
\hline UV-B & $5(10)$ & 2.30 & 0.121 & 2.56 & 0.096 & 1.63 & 0.239 \\
\hline Block (B) & 2 (18) & 0.28 & 0.761 & 0.88 & 0.432 & 0.10 & 0.910 \\
\hline $\mathrm{UV}-\mathrm{B} \times \mathrm{B}$ & $10(18)$ & 0.83 & 0.609 & 0.80 & 0.635 & 3.03 & 0.020 \\
\hline \multicolumn{8}{|l|}{ October } \\
\hline UV-B & $5(10)$ & 1.44 & 0.291 & 1.10 & 0.420 & 1.23 & 0.365 \\
\hline Block (B) & 2 (18) & 0.88 & 0.433 & 0.37 & 0.697 & 0.12 & 0.888 \\
\hline UV-B $\times B$ & 10 (18) & 2.23 & 0.067 & 1.11 & 0.409 & 1.58 & 0.193 \\
\hline
\end{tabular}

explained almost $32 \%$ of the variance (quadratic polynomial regression, $\mathrm{r}=0.565, \mathrm{p}<0.001$, Fig. 3). In July, the pattern for species richness along the eUV-BR gradient was very similar to that found for diversity. A significant unimodal relationship between species richness and eUV-BR treatments explained about $31 \%$ of the variance (quadratic polynomial regression, $\mathrm{r}=$ 0.554, $\mathrm{p}<0.001$, Fig. 3). Species richness first increased with longer eUV-BR exposure to a maxima on $1 \mathrm{~h}$ exposed panels, and fell on panels with $>1 \mathrm{~h}$ exposure. Despite the significant unimodal pattern, species richness was just not significantly different among treatments (ANOVA, $\left.F_{5,30}=4.12, \mathrm{p}=0.0055\right)$. Between
August and October, neither species richness nor diversity showed a significant unimodal pattern or significant differences among treatments.

Although biodiversity parameters were never or only temporarily affected by our treatments, significant effects on species composition were found for 4 of the 5 sampling dates. In June, $80 \%$ of the community was composed of the brown alga Pilayella litoralis and green seaweeds. While the brown alga dominated communities exposed to $\leq 2 \mathrm{~h}$ eUV-BR, green algae covered on average $60 \%$ of panels treated for 4 and $8 \mathrm{~h}$ with eUV-BR (Fig. 4). Species composition was significantly affected by eUV-BR exposure at that time in 
community succession (ANOSIM, $R=0.335, \mathrm{p}=0.001$ ). Pairwise comparisons revealed a significant dissimilarity between communities exposed to 1 and $4 \mathrm{~h}$ treatments, 1 and $8 \mathrm{~h}$ treatments, and between 2 and $4 \mathrm{~h}$ treatments. SIMPER analysis detected that $P$. litoralis and green algae together explained over $80 \%$ of the observed dissimilarity, with negative UV-BR effects on the brown alga and positive UV-BR effects on green algae.

In July, all communities treated with eUV-BR were dominated by green algae, which encompassed on average $50 \%$ of the communities (Fig. 4). Species composition was significantly affected by eUV-BR (ANOSIM, $R=0.182, \mathrm{p}=0.002$ ). Pairwise comparisons indicated significant effects of eUV-BR exposure on species composition between communities on control and $4 \mathrm{~h}$-exposed panels, control and $8 \mathrm{~h}$-exposed panels, and between 1 and 8 h-exposed panels. Mussels and green and red algae together explained more than $70 \%$ of the observed dissimilarity (SIMPER). eUV-BR exposure was positive for green seaweeds and mussels, but negative for red algae.

While in August effects of eUV-BR did not affect species composition (ANOSIM, $R=-0.023, \mathrm{p}>0.6$ ), eUVBR effects were significantly different among treatments in September (ANOSIM, $R=0.170, \mathrm{p}=0.001$ ). Pairwise comparisons revealed significant eUV-BR effects on species composition between 1 and $4 \mathrm{~h}$ exposed panels, and between $2 \mathrm{~h}$ and $8 \mathrm{~h}$-exposed panels. Green and red algae explained together over $50 \%$ of the detected dissimilarity (SIMPER), with positive effects on green and detrimental effects on red algae.

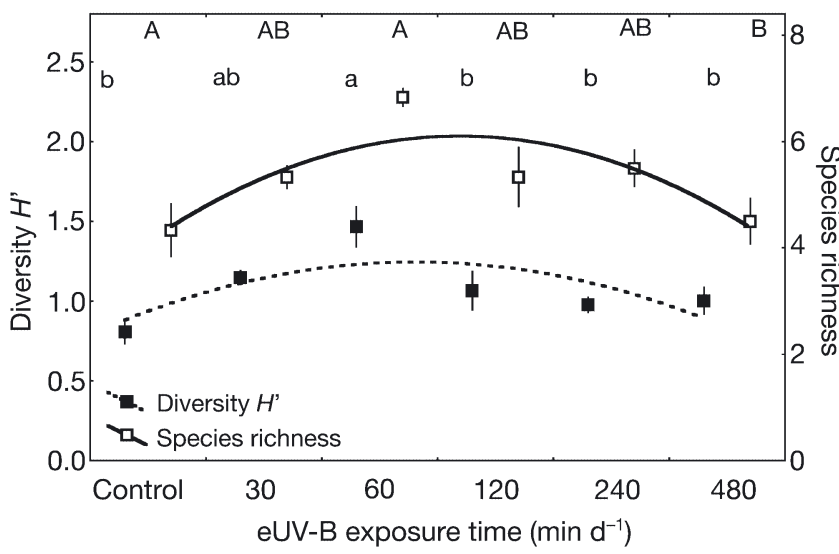

Fig. 3. Effects of eUV-BR exposure to species richness and diversity $H^{\prime}$ (mean $\pm \mathrm{SE}, \mathrm{n}=6$ ) in July and respective lines of best fit from quadratic polynomial regression analysis. Capital and lower-case letters indicate treatment differences analysed with ANOVA for species richness and diversity, respectively; treatments sharing a letter are not significantly different
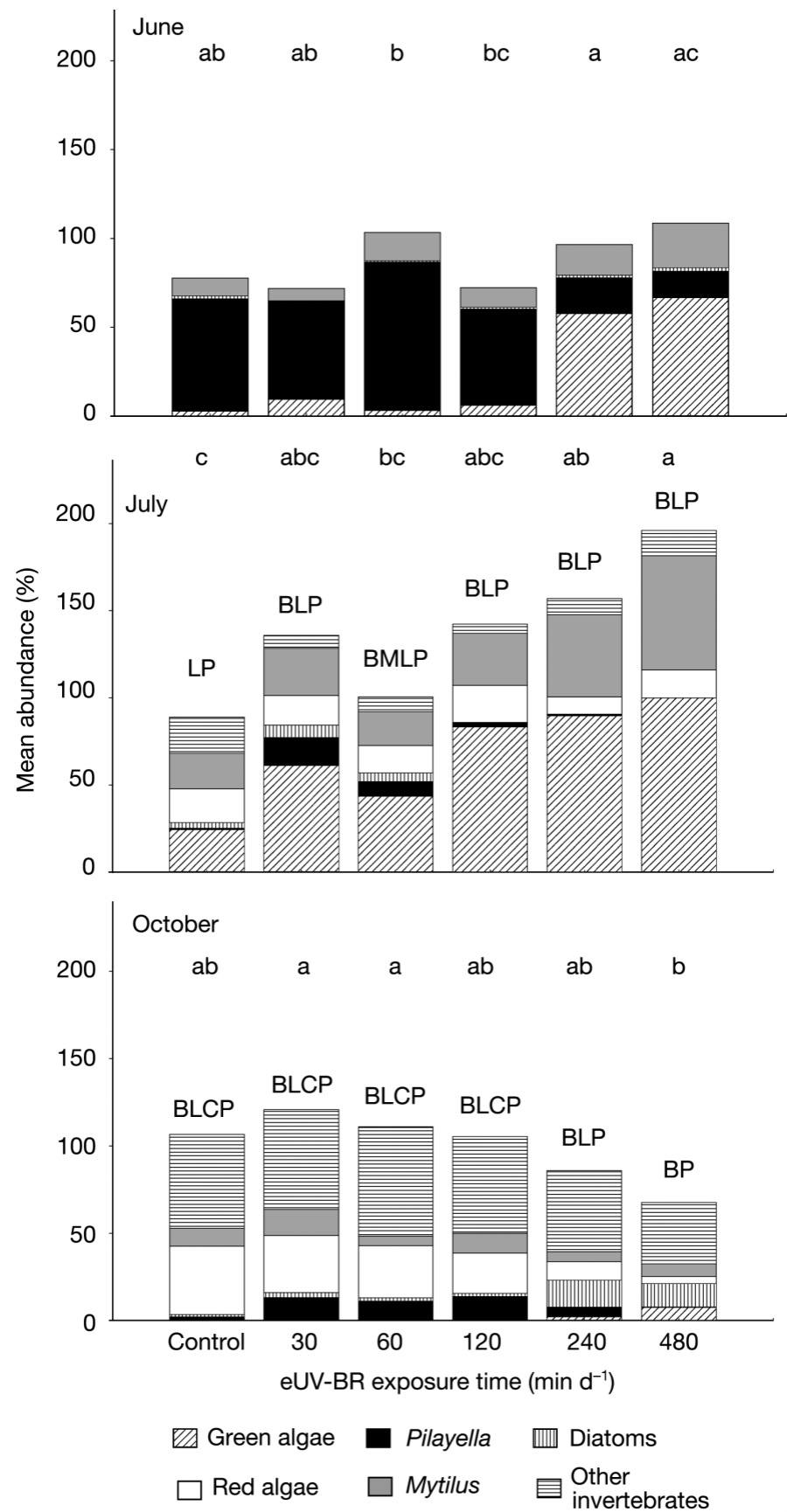

Fig. 4. Effects of eUV-BR exposure on mean percent cover of selected species and taxonomic groups $(n=6)$ in June, July, and October 2000. Green and red algae cover always comprised $>95 \%$ Ulvopsis grevillei and Ceramium strictum, respectively. Invertebrate cover in July consisted of $>72 \%$ the hydroid Laomedea flexuosa and $>22 \%$ the polychaete Polydora ciliata. In October, P. ciliata and the barnacle Balanus improvisus comprised over $54 \%$ and $31 \%$ of invertebrate cover, respectively. Lower-case letters indicate differences in species composition among treatments: interpretation as in Fig. 3. Capital letters indicate species presence: $\mathrm{B}=$ Balanus improvisus, $\mathrm{C}=$ Clava multicornis, $\mathrm{L}=$ Laomedea flexuosa, $\mathrm{M}=$ Membranipora membranacea, $\mathrm{P}=$ Polydora ciliata 
Table 5. Mytilus edulis and Ulvopsis grevillei. Mixed-model ANOVA of effects of enhanced UV-BR and block on mussel density (individuals $\mathrm{cm}^{-2}$ ) and alga abundance for monthly sampling dates between June and October. Numbers in parentheses: df of error terms; na: not applicable

\begin{tabular}{|lcccrcr|}
\hline \multirow{2}{*}{ Source } & \multirow{2}{*}{$\mathrm{df}$} & \multicolumn{3}{c}{ Mytilus edulis } & \multicolumn{3}{c}{ Ulvopsis } & grevillei \\
& & $F$ & $\mathrm{p}$ & $F$ & $\mathrm{p}$ \\
\hline June & & & & & \\
UV-B & $5(10)$ & 8.06 & 0.003 & 47.72 & $<0.001$ \\
Block (B) & $2(18)$ & 0.58 & 0.569 & 0.99 & 0.390 \\
UV-B $\times$ B & $10(18)$ & 1.802 & 0.133 & 1.72 & 0.153 \\
July & & & & & \\
UV-B & $5(10)$ & 8.96 & 0.002 & 9.88 & 0.01 \\
Block (B) & $2(18)$ & 0.72 & 0.502 & 0.44 & 0.649 \\
UV-B $\times$ B & $10(18)$ & 0.641 & 0.761 & 0.735 & 0.685 \\
August & & & & & \\
UV-B & $5(10)$ & 1.44 & 0.291 & 0.19 & 0.959 \\
Block (B) & $2(18)$ & 1.49 & 0.253 & 1.36 & 0.282 \\
UV-B $\times$ B & $10(18)$ & 1.31 & 0.296 & 1.42 & 0.249 \\
September & & & & & \\
UV-B & $5(10)$ & 4.68 & 0.018 & 14.85 & $<0.001$ \\
Block (B) & $2(18)$ & 2.084 & 0.154 & 2.61 & 0.102 \\
UV-B $\times$ B & $10(18)$ & 0.62 & 0.777 & 0.54 & 0.836 \\
October & & & & & \\
UV-B & $5(10)$ & 0.61 & 0.693 & na & na \\
Block (B) & $2(18)$ & 1.77 & 0.199 & na & na \\
UV-B $\times$ B & $10(18)$ & 2.768 & 0.029 & na & na \\
& & & & & \\
\hline
\end{tabular}

In October, both red algae and the polychaete Polydora ciliata dominated, constituting on average over $50 \%$ of the communities (Fig. 4). Species composition was significantly different (ANOSIM, $R=0.297, \mathrm{p}=$ 0.001 ) between communities of $30 \mathrm{~min}$ and $8 \mathrm{~h}$ eUV-BR exposure, and between $1 \mathrm{~h}$ and $8 \mathrm{~h}$ exposure. Red algae, the hydroid Laomedea flexuosa and the brown alga Pilayella litoralis contributed together, on average, over $50 \%$ to this difference in species composition. Positive UV-BR effects were only observed for the brown seaweed.

\section{Mussel density and Ulvopsis abundance}

Neither mussel density nor Ulvopsis abundance was significantly different between controls and procedural controls at any time during community succession. Block effects were missing (Table 5).

Averaged over all treatments, mussel density was highest during settlement in July, with $94.3 \pm 58.3$ individuals $\mathrm{cm}^{-2}$ (mean $\pm \mathrm{SD}, \mathrm{n}=6$ ), and declined monotonically until the end of the experiment (Fig. 5). Significant treatment effects on mussel density were limited to the first
2 mo of the succession. In June, a significant positive relationship between mussel density and eUV-BR exposure time was detected (linear regression, $\mathrm{r}=0.69$, $\mathrm{p}<0.01$ ). Differences among eUV-BR treatment effects on mussel density were significant (Table 5). Multiple comparisons revealed that mussel density was favoured after $8 \mathrm{~h}$ eUV-BR exposure compared to panels with $\leq 2 \mathrm{~h}$ exposure (Fig. 5). In July, this pattern consolidated when mussel density was significantly higher on $>4$ h-treated panels (Fig. 5). Again, a significant positive relationship between mussel density and eUV-BR exposure time was observed (linear regression, $r=0.62, p<0.01)$. Beyond the second month in the community succession, mussel density was neither significantly related to eUV-BR, nor were significant differences among eUV-BR treatments detected.

Averaged over all treatments, cover of the green algae Ulvopsis peaked in July $(59.2 \pm 39.4 \%)$, declined during the subsequent month to $9.3 \pm 10.1 \%$, and was sparse during the rest of the experiment. Ulvopsis cover significantly increased with eUV-BR exposure time in June (linear regression, $r=0.82, p<0.01$, Fig. 4) and July (linear regression, $r=0.73, p<0.01$, Fig. 4). In August, no significant effects of eUV-BR on Ulvopsis abundance were found. In September, Ulvopsis cover increased significantly with increasing eUV-BR exposure (linear regression, $r=0.59, \mathrm{p}<0.01$ ).

A significant correlation between mussel density and Ulvopsis abundance was detected in July (Spearman's rank, $\mathrm{r}=0.986, \mathrm{p}<0.01$ ).

\section{DISCUSSION}

Altogether, enhanced UV-B radiation (eUV-BR) affected community diversity on our panels only slightly, yet our experiment disclosed transitory unimodal patterns for diversity and species richness along the

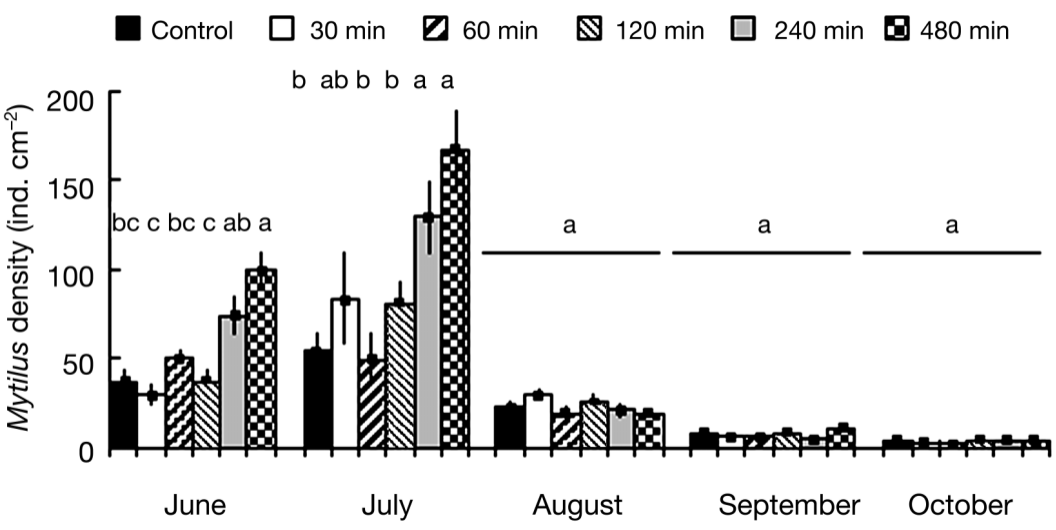

Fig. 5. Mytilus edulis. Monthly effects of eUV-BR exposure on density (mean \pm $\mathrm{SE}, \mathrm{n}=6$ ) between June and October 2000; lower-case letters as in Fig. 3. Lines below a letter group = non-significant treatments 
eUV-BR gradient. Mussel density and Ulvopsis cover were positively correlated in July, with both parameters increasing along the eUV-BR gradient. While most of these effects were restricted to the first $2 \mathrm{mo}$, eUV-BR affected species composition strongly throughout the entire experimental phase.

\section{Radiation measurements}

When averaged over the entire study period, the energy flux of lamps $10 \mathrm{~cm}$ below the surface was $54 \%$ above ambient levels at noon. To date, a yearly increase in ozone-related UV-BR of $1.5 \%$ has been deduced from ground-based measurements at $40^{\circ}$ latitude (WMO 1998), which may (van der Leun et al. 1995, Tabazadeh et al. 2000) or may not (Montzka et al. 1999, Austin et al. 2000) last until the middle of this century. Thus, at the water depth where settlement panels were deployed, the energy flux of lamps could match expected maximum UV-BR fluxes around the middle of this century, permitting an assessment of how extant communities will respond to expected future ozone-related ambient UV-BR levels at different daily doses. Nevertheless, by setting the artificial radiation regime at a constant level with reference to local noon, we enhanced UV-BR levels beyond $54 \%$ of ambient levels for times when solar elevation was lower. Further, $K_{\mathrm{d}}$ values for UV-BR measured in this study represent average water transparency in the Baltic Sea as opposed to lowest (3 to 3.5 in Wängberg et al. 1996, Franklin \& Forster 1997) and highest ( $>28$ in Piazena \& Häder 1994) values. As a result of temporal changes in water transparency, the investigated communities experienced both a turbidity-mediated enhancement as well as mitigation of UV-BR exposure. Although none of these factors would affect relative UV-BR effects among treatments, an extrapolation of absolute effects should be made with caution.

\section{Effects on species composition and community diversity}

In contrast to earlier assumptions (Jokiel 1980, Häder et al. 1995), our study did not show detrimental UV-BR effects on the diversity of the macrobenthic fouling community studied. More recently, an (albeit limited) number of studies were also unable to confirm inhibitory UVR effects on benthic community diversity (DeNicola \& Hoagland 1996, Keller et al. 1997, Kiffney et al. 1997, Santas et al. 1998, Lotze et al. 2002). This startling lack of UVR effects on the diversity of macrobenthic communities contradicts the large number of detrimental UVR effects reported at the organismal and species level, with some of the latter effects also apparent at our study site (Wängberg et al. 1996, Franklin \& Forster 1997, Häder et al. 1998, Aguilera et al. 1999, Karentz \& Bosch 2001, Montero et al. 2002).

Pre-acclimatization of dispersal stages to UVR stress has been shown previously (Wiencke et al. 2000). The possibility of selective recruitment of already UV-BRadapted dispersal stages from shallow-water areas does not explain the missing UV-BR effects in our study. Typically, the penetration depth of UV-BR is $<50 \mathrm{~cm}$ below the surface (M. Molis unpubl. data), whereas vertical water movements are in the range of metres (Magaard 1974), entraining dispersal stages from UV-BR-free areas to surface waters. Instead, our work suggests that the community response to UV-BR is not necessarily equal to the sum of UV-BR effects on individual species. In this context, the green foliose alga Ulvopsis grevillei seems to modulate UV-BR effects on the fouling community investigated. UV-BR stimulated Ulvopsis development, probably due to an extra energy gain or a lack of UV-B-sensitive competitors and/or grazers. The ability to cope well with high irradiance levels has been shown for the ecologically and taxonomically closely related intertidal green alga Ulva lactuca (Grobe \& Murphy 1998, Altamirano et al. 2000, Karsten et al. 2001). Consequently, the Ulvopsis canopy covered progressively more substratum along the UV-BR gradient, presumably increasing the settlement area suitable for UV-R-sensitive fouling organisms. Work on other types of assemblages corroborates this assumption. For instance, protective shading of UV-R-resistant species in the outer layers of microalgal assemblages explained the absence of adverse UVR effects despite high levels of UV-BR within diatom assemblages (Sundbäck et al. 1996, Karsten et al. 1998), and may also confer resistance on macrobenthic recruits (Lotze et al. 2002).

Although Ulvopsis abundance increased steadily with increasing eUV-BR exposure time, species richness and diversity did not. Instead, both species richness and diversity stayed at a constant level or displayed unimodal patterns along the eUV-BR gradient, as predicted by the IDH (Connell 1978). There is some controversy about how to define the term 'disturbance'. Following the definition of Grime (1977), a disturbance is characterised by a loss of biomass. As previously shown, early life stages may display a higher susceptibility to UV-BR than adults (Santas et al. 1998, Lotze \& Worm 2002) and thus, as a single factor, UV-BR cannot be said to affect a community at all times and in all places, and cannot therefore be deemed a disturbance sensu Grime (1977). Early in community succession, UV-BR impacts as a disturbance, but for mature organisms it represents a stress factor. As a consequence, for most, if not all environmental factors, a 
clear separation of disturbance and stress agents is not possible when monitoring their effects on communities during community succession. We regarded UV-BR as a disturbance in our study because of its high potential to destroy biomass during early succession, i.e. the period when our experiment was conducted.

The processes which cause a decline in diversity under the low and high disturbance regime in our study (i.e. a harsh UV-BR-disturbance regime and dominance of competitively superior species) are identical to those predicted by the original model, but appear to be reversed from left to right along the UV-BR gradient (Fig. 6). Dominance by mussels and Ulvopsis (and not, as predicted by the IDH, the harshness of disturbance conditions) lowered diversity during the longest exposure times. Despite the UV-BR sensitivity of veliger larvae (Chalker-Scott et al. 1994), Ulvopsis may have enhanced mussel recruitment at the most intense UV-BR regime due to protective shading by its canopy and provision of suitable settlement cues such as physical structures (Dayton 1971, Pulfrich 1996). These settlement conditions may have been favourable for dispersal forms of other species also, but as our data indicate, the density of mussel spat was high enough to cover all the substratum, probably suffocating recruits of other species. In a previous study at the same site, dominance of mussels with the onset of

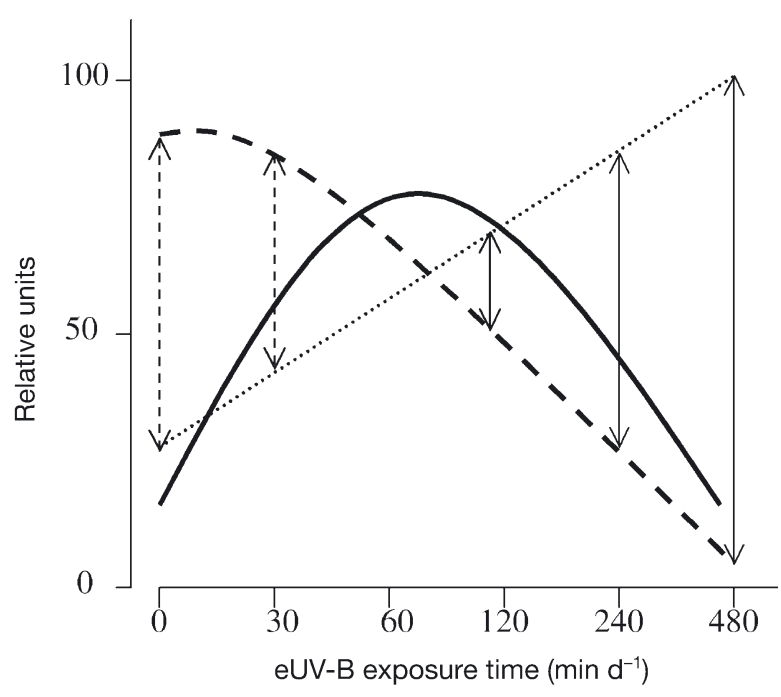

Fig. 6. Mytilus edulis and Ulvopsis grevillei. Schematic trends of mussel abundance (dotted line), harshness of the UV-BR gradient (dashed line) and diversity $H^{\prime}$ (continuous line) along eUV-BR gradient. Lengths of arrows indicate strength of diversity-reducing impact due to (1) detrimental UV-BR (dashed arrows) and (2) dominance of mussel $M$. edulis and the competitive superior alga $U$. grevillei (continuous arrows); maximum diversity occurs at eUV-BR exposure times with intermediate levels of (1) UV-BR and (2) U. grevillei and mussel abundance, respectively spat falls was the major reason for declining diversity (S. Dürr unpubl. data). Loss of species at the lower end of the disturbance gradient indicates that even ambient irradiance can be detrimental for UV-R-sensitive species. Moreover, the potential for protective shading by Ulvopsis cover was minimal under ambient irradiance and increased constantly with longer eUV-BR exposure. Thus, the irradiance regime at the lower end of the disturbance gradient represented the relatively harsh UV-BR environment in our experiment (Fig. 6). The positive effect of Ulvopsis on UV-sensitive species at the lower end of the eUV-BR gradient will be overridden by the negative effects due to a dominance of Ulvopsis and mussels at the high end of the gradient.

Although our work corroborates the predictions of the IDH, it also indicates the difficulty, in community studies, of relating the actual disturbance impact on a community (e.g. on its diversity) to the physically measurable strength of a disturbing factor, e.g. the energy flux of UV-BR. Innocuous disturbance effects on certain species, or indirect effects (e.g. protective shading) may compensate to varying degrees for the disturbing character of UV-BR.

The transient nature of UV-BR effects on diversity further suggests a minor ecological relevance of UV$\mathrm{BR}$ in our study system relative to other factors. We speculate that grazing effects outranked UV-BR effects. A 6-fold decline in Ulvopsis cover across all treatments between July and August suggests high seasonal grazing pressure on this green alga. Unfortunately, we did not estimate the abundance of consumers. Nevertheless, mesograzers can strongly depress the abundance of early life stages and of adult macroalgae (Brawley 1992, Duffy \& Hay 2000, Lotze \& Worm 2000). For the Baltic Sea, gammarid amphipods and isopods are seen as a keystone guild which maintains the coexistence of macroalgae (Worm \& Karez 2002). This guild may obscure potential differences in diversity of differently treated macroalgae-dominated communities if the grazers themselves are unaffected by such treatment. An experiment that controls for the interactive effects of eUV-BR and consumers would be most valuable in clarifying the relative ecological relevance of both factors.

In contrast to transient UV-BR effects on diversity parameters, effects on species composition persisted, indicating the reduced ability to detect changes in community composition with univariate compared to multivariate parameters. Species composition was most strongly affected by the longest eUV-BR exposure. Treatment effects were consistently negative for red and positive for green seaweeds. Brown algae were intermediate in their response to UV-BR exposure: at the beginning of the experiment effects were negative, but in October brown seaweeds benefited 
from UV-BR exposure. This differential UVR sensitivity in macroalgae is reflected in the natural vertical distribution of algae at our study site (pers. obs.) and has been reported to affect competitiveness among seaweeds at other sites (Karsten et al. 2001, Lotze et al. 2002). A higher initial sensitivity to UV-BR of Pilayella litoralis in our study corroborates the results of other studies on brown algae in which the same temporal pattern was detected (Santas et al. 1998, Lotze et al. 2002). We speculate that the consistency of detrimental UV-BR effects on red algae at our study site was caused by either an inability to adapt to changing irradiance regimes or the inability to develop protective or repair mechanisms at ecologically relevant times. This marks red algae as the group which may suffer strongest from future increases in UV-BR, whereas green algae will benefit strongly from future increases in UV-BR at our study site, at least until mussels dominate the substratum or green algae are consumed. As a consequence, green algae may retreat to greater water depth, replacing red algae.

In conclusion, UV-BR effects at our study site were transitory for diversity and persistent in species composition over the 5 mo experimental period. A shortterm appearance of unimodal diversity patterns confirmed the IDH, but the processes responsible for its generation were the reverse of those predicted by the model. Unlike green algae, red algae were in particular adversely affected by our treatments, suggesting shifts in the vertical distribution of green and red algae if future UV-BR levels continue to increase.

Acknowledgements. We thank Pausch Ltd. for the gratis supply of UV-B lamps. We are most thankful to the workshop staff of the Biozentrum Kiel University for their help in designing and constructing the experimental set-up. We acknowledge technical support by the staff of the Schleuseninsel, Kiel-Holtenau, and the WSA Kiel-Holtenau for admission to the study site and administrative support. We gratefully thank C. H. Stick and H. Sandmann for utilisation of a spectroradiometer and essential help during measurements. We are thankful to M. Zimmer and H. Hillebrand for comments on the manuscript. We acknowledge the grants Wa 708/ 6-1 + 6-2 of the Deutsche Forschungsgemeinschaft (DFG) to M.W.

\section{LITERATURE CITED}

Aguilera J, Jimenez C, Figueroa F, Lebert M, Häder DP (1999) Effect of ultraviolet radiation on thallus absorption and photosynthesis pigments in the red alga Porphyra umbilicalis. J Photochem Photobiol B Biol 48:75-82

Altamirano M, Flores-Moya A, Figueroa F (2000) Long-term effects of natural sunlight under various ultraviolet radiation conditions on growth and photosynthesis of intertidal Ulva rigida (Chlorophyceae) cultivated in situ. Bot Mar 43: 119-126

Aronson R, Precht W (1995) Landscape patterns of reef coral diversity: a test of the intermediate disturbance hypothesis. J Exp Mar Biol 192:1-14

Austin J, Knight J, Butchart N (2000) Three-dimensional chemical model simulations of the ozone layer: 1979-2015. Q J R Meteorol Soc Part B 126:1533-1556

Bothwell M, Sherbot D, Roberge A, Daley R (1993) Influence of natural ultraviolet radiation on lotic periphytic diatom community growth, biomass accrual, and species composition: short-term versus long-term effects. J Phycol 29: 24-35

Bothwell M, Sherbot D, Pollock C (1994) Ecosystem response to solar ultraviolet-B radiation: influence of trophic-level interactions. Science 265:97-100

Brawley S (1992) Mesoherbivores. In: John S, Hawkins S, Price J (eds) Plant-animal interactions in the marine benthos. Clarendon Press, Oxford, p 235-263

Chalker-Scott L, Scott J, Titus J (1994) Brief exposure to ultraviolet radiation inhibits locomotion of veligers and juvenile D. polymorpha. In: Int Ass Great Lakes Research and Estuarine Research Federation. Abstracts of the 37th conference. Buffalo, NY, p 166

Connell JH (1978) Diversity in tropical rain forests and coral reefs. Science 199:1302-1310

Dayton P (1971) Competition, disturbance, and community organization: the provision and subsequent utilization of space in a rocky intertidal community. Ecol Monogr 41: 351-389

DeNicola D, Hoagland K (1996) Effects of solar spectral irradiance (visible to UV) on a prairie stream epilithic community. J North Am Benthol Soc 15:155-169

Duffy J, Hay M (2000) Strong impacts of grazing amphipods on the organisation of a benthic community. Ecol Monogr 70:237-263

Edwards P, Abivardi C (1998) The value of biodiversity: where ecology and economy blend. Biol Conserv 83:239-246

Ehrlich PR, Wilson EO (1991) Biodiversity studies: science and policy. Science 253:758-762

Emmerson M, Solan M, Emes C, Paterson D, Raffaelli D (2001) Consistent patterns and the idiosyncratic effects of biodiversity in marine ecosystems. Nature 411:73-77

Flöder S, Sommer U (1999) Diversity in planktonic communities: an experimental test of the intermediate hypothesis. Limnol Oceanogr 44:1114-1119

Fox J (1981) Intermediate levels of soil disturbance maximize alpine plant diversity. Nature 293:564-565

Franklin LA, Forster RM (1997) The changing irradiance environment: consequences for marine macrophyte physiology, productivity and ecology. Eur J Phycol 32: 207-232

Grime J (1977) Evidence for the existence of three primary strategies in plants and its relevance to ecological and evolutionary theory. Am Nat 111:1169-1194

Grobe C, Murphy T (1998) Solar ultraviolet-B radiation effects on growth and pigment composition of the intertidal alga Ulva expansa (Setch.) S. \& G. (Chlorophyta). J Exp Mar Biol Ecol 225:39-51

Häder DP, Worrest R, Kumar H, Smith R (1995) Effects of increased solar ultraviolet radiation on aquatic ecosystems. Ambio 24:174-180

Häder DP, Kumar HD, Smith RC, Worrest RC (1998) Effects on aquatic ecosystems. In: Environmental effects of ozone depletion-1998 Assessment. United Nations Environment Programme, Nairobi, p 86-112

Hardin G (1960) The competitive exclusion principle. Science 113:1292-1298

Hughes J, Daily G, Ehrlich P (1997) Population diversity: its extent and extinction. Science 278:689-692 
Hutchinson G (1961) The paradox of the plankton. Am Nat 95: 137

Jokiel P (1980) Solar ultraviolet radiation and coral reef epifauna. Science 207:1069-1071

Karentz D, Bosch I (2001) Influence of ozone-related increases in ultraviolet radiation on Antarctic marine organisms. Am Zool 41:3-16

Karsten U, Maier J, Garcia-Pichel F (1998) Seasonality in UVabsorbing compounds of cyanobacterial mat communities from an intertidal mangrove flat. Aquat Microb Ecol 16: $37-44$

Karsten U, Bischof K, Wiencke C (2001) Photosynthetic performance of Arctic macroalgae after transplantation from deep to shallow waters. Oecologia 127:11-20

Keller A, Hargraves P, Jeon H, Klein-MacPhee G, Klos E, Oviatt C, Zhang J (1997) Ultraviolet-B radiation enhancement does not affect marine trophic levels during a winter-spring bloom. Mar Biol 130:277-287

Kiffney P, Clements W, Cady T (1997) Influence of ultraviolet radiation on the colonization dynamics of a Rocky Mountain stream benthic community. J North Am Benthol Soc 18:520-530

Lotze H, Worm B (2000) Variable and complementary effects of herbivores on different life stages of bloom-forming macroalgae. Mar Ecol Prog Ser 200:167-175

Lotze H, Worm B (2002) Complex interactions of climatic and ecological controls on macroalgal recruitment. Limnol Oceanorgr 47:1734-1741

Lotze H, Worm B, Molis M, Wahl M (2002) Effects of UV radiation and consumers on recruitment and succession of a marine macrobenthic community. Mar Ecol Prog Ser 243: $57-66$

Mackey R, Currie D (2001) The diversity-disturbance relationship: is it generally strong and peaked? Ecology 82: 3479-3492

Magaard L (1974) Wasserschwankungen und Seegang. In: Magaard L, Rheinheimer G (eds) Meereskunde der Ostsee. Springer-Verlag, Berlin, p 67-77

McCabe D, Gotelli N (2000) Effects of disturbance frequency, intensity, and area on assemblages of stream macroinvertebrates. Oecologia 124:270-279

McGrady-Steed J, Harris P, Morin P (1997) Biodiversity regulates ecosystem predictability. Nature 390:162-165

Menge B, Sutherland J (1987) Community regulation: variation in disturbance, competition, and predation in relation to environmental stress and recruitment. Am Nat 130: $730-757$

Molis M (2002) Shallow water fouling assemblages exposed to abiotic disturbance and stress: the structuring role of emersion and UV-radiation. PhD thesis, ChristianAlbrechts University, Kiel

Montero O, Klisch M, Häder DP, Lubian L (2002) Comparative sensitivity of seven marine microalgae to cumulative exposure to ultraviolet-B radiation with daily increasing doses. Bot Mar 45:305-315

Montzka S, Butler J, Elkins J, Thompson T, Clarke A, Lock L (1999) Present and future trends in the atmospheric burden of ozone-depleting halogens. Nature 398:690-694

Mook D (1981) Effects of disturbance and initial settlement on fouling community structure. Ecology 62:522-526

Naeem S, Li S (1997) Biodiversity enhances ecosystem reliability. Nature 390:507-509

Naeem S, Thompson L, Lawler S, Lawton J, Woodfin R (1994) Declining biodiversity can alter the performance of ecosystems. Nature 368:734-737

Pavia H, Cervin G, Lindgren A, Åberg P (1997) Effects of UV-B radiation and simulated herbivory on phlorotannins in the brown alga Ascophyllum nodosum. Mar Ecol Prog Ser 157:139-146

Piazena H, Häder DP (1994) Penetration of solar UV irradiation in coastal lagoons of the southern Baltic Sea and its effect on phytoplankton communities. Photochem Photobiol 60:463-469

Pickett S, Kolasa J, Armesto J, Collins S (1989) The ecological concept of disturbance and its expression at various hierarchical levels. Oikos 54:129-136

Pimm S, Russell G, Gittleman J, Brooks T (1995) The future of biodiversity. Science 269:347-350

Pulfrich A (1996) Attachment and settlement of post-larval mussels (Mytilus edulis L.) in the Schleswig-Holstein Wadden Sea. J Sea Res 36(3-4):239-250

Quinn G, Keough M (2002) Experimental design and data analysis for biologists. Cambridge University Press, Cambridge

Reynolds C, Padisak J, Sommer U (1993) Intermediate disturbance in the ecology of phytoplankton and the maintenance of species diversity: a synthesis. Hydrobiologia 249: $183-188$

Santas R, Korda A, Lianou C, Santas P (1998) Community responses to UV radiation. I. Enhanced UV-B effects on biomass and community structure of filamentous algal assemblages growing in a coral reef mesocosm. Mar Biol 131:153-162

Schindler D, Curtis P, Parker B, Stainton M (1996) Consequences of climate warming and lake acidification for UV-B penetration in North American boreal lakes. Nature 379:705-708

Setlow R (1974) The wavelengths in sunlight effective in producing skin cancer: a theoretical analysis. Proc Natl Acad Sci USA 71:3363-3366

Smith F, Witman J (1999) Species diversity in subtidal landscapes: maintenance by physical processes and larval recruitment. Ecology 80:51-69

Sokal RR, Rohlf FJ (1995) Biometry: the principles and practice of statistics in biological research. WH Freeman, New York

Sundbäck K, Nilsson C, Odmark S, Wulff A (1996) Does ambient UV-B radiation influence marine diatom-dominated microbial mats? A case study. Aquat Microb Ecol 11: 151-159

Tabazadeh A, Santee M, Danilin M, Pumphrey H, Newman P, Hamill P, Mergenthaler J (2000) Quantifying denitrification and its effect on ozone recovery. Science 288: 1407-1411

Tanner JE, Hughes TP, Connell JH (1994) Species coexistence, keystone species, and succession: a sensitivity analysis. Ecology 75:2204-2219

Tilman D, Downing J (1994) Biodiversity and stability in grasslands. Nature 367:363-365

Tilman D, May RM, Lehman CL, Nowak MA (1994) Habitat destruction and the extinction debt. Nature 371:65-66

Tilman D, Wedin D, Knops J (1996) Productivity and sustainability influenced by biodiversity in grassland ecosystems. Nature 379:718-720

van der Leun J, Tang X, Tevini M (1995) Environmental effects of ozone depletion: 1994 assessment. Ambio 24:138-142

Vitousek P, Mooney H, Lubchenco J, Melillo J (1997) Human domination of earth's ecosystems. Science 277:494-499

Wängberg SA, Selmer JS, Ekelund NGA, Gustavson K (1996) UV-B effects on nordic marine ecosystems: a literature review. Nordic Council of Ministers, Copenhagen

White P, Pickett S (1985) Natural disturbance and patch dynamics: an introduction. In: Pickett S, White P (eds) The ecology of natural disturbance and patch dynamics. Academic Press, Orlando, p 3-13 
Wiencke C, Gomez I, Pakker H, Flores-Moya A, Altamirano M, Hanelt D, Bischof K, Figueroa F (2000) Impact of UVradiation on viability, photosynthetic characteristics and DNA of brown algal zoospores: implication for depth zonation. Mar Ecol Prog Ser 197:217-229

Winer B, Brown D, Michels K (1991) Statistical principles in experimental design. McGraw-Hill, New York

Wood W (1987) Effect of solar ultra-violet radiation on the

Editorial responsibility: Otto Kinne (Editor),

Oldendorf/Luhe, Germany kelp Ecklonia radiata. Mar Biol 96:143-150

World Meteorological Asociation (WMO) (1998) Scientific assessment of ozone depletion, World Meteorological Organisation, Geneva

Worm B, Karez R (2002) Competition, coexistence and diversity on rocky shores. In: Sommer U, Worm B (eds) Competition and coexistence. Springer-Verlag, Berlin, p 133-163

Submitted: March 19, 2003; Accepted: August 26, 2003

Proofs received from author(s): November 24, 2003 